\title{
Flipped Classroom Activity Using the PTA Model in an Introductory Sociology Course
}

\author{
Lauren M. Sardi* \\ February 20, 2018
}

\begin{abstract}
This scaffolded writing-to-learn activity incorporates a number of Writing Across the Curriculum-based suggestions that draw upon the strengths of student reflection, the PTA (prioritization, translation, and analogization) model of concentric thinking, and the benefits of a flipped-classroom approach to learning. Thus, the purpose of this article is to explain what one model for structuring a flipped classroom that purposefully integrates writing in the PTA model looks like and to provide a concrete example of a flipped-classroom activity that I have utilized in numerous introductory sociology courses.
\end{abstract}

\section{Introduction}

Recent literature has focused on the development and benefits of a flipped classroom (Fulton, 2012; Sams \& Bergmann, 2011). However, the majority of that literature is devoted to research conducted primarily in STEM-focused courses (Berrett, 2012; Brame, 2013; Moore, Gillett, \& Steele, 2014). There appears to be very little research on the context or benefits of a flipped classroom in the social sciences, including sociology.

While lecturing is the most traditional approach to teaching in a college classroom, some research in the areas of critical thinking support the notion that lecturing is not necessarily the most effective method of cultivating critical thinking among college students. While lecturing is often the most comfortable and normative experience for both professors and students alike, further research by Huggins and Stamatel (2015) discusses the complicated differences between lecturing and team-based learning through an exploratory study, while Rickles, Schneider, Slusser, Williams, and Zipp (2013) demonstrate that using writing such as scaffolded assignments, as well as class discussion, significantly increases

\footnotetext{
*Department of Sociology, Quinnipiac University, Lauren.Sardi@quinnipiac.edu. Copyright 2018 Lauren Sardi. This work is licensed under a Creative Commons Attribution-NonCommercial 4.0 International License (http://creativecommons.org/licenses/by-nc/4.0/).

${ }^{\dagger}$ Submitted, 5/23/2017; Accepted, 11/10/2017
} 
objectively measured student critical thinking skills. Thus, a flipped classroom approach may be a more efficient and engaging way of teaching critical thinking skills. Using writing to engage students in critical thinking is also an important part of both the discipline of sociology as well as to the flipped classroom approach in general. One such approach, the PTA model of concentric thinking, articulates a theoretical framework that involves the scaffolding of cognitive tasks including prioritization, translation, and analogization (Hudd, Smart, \& Delohery, 2011).

\section{Prioritization, Translation, and Analogization: Concentric Thinking}

When referring to the PTA model of concentric thinking, I am specifically referring to Hudd, Smart, and Delohery's (2011) pedagogical approach that implements a hierarchical way of thinking using three types of linked tasks: prioritization, translation, and analogization. In this approach, students are purposefully led through scaffolded informal writing activities that build upon the competencies developed from the previous task. Thus, the first general writing activity tasks students with prioritizing important or relevant information from course readings or discussions. While students can often feel overwhelmed with blocks of texts, the first level of this activity guides students toward identifying information that is pertinent to the author's overall argument or toward a student's intended analysis.

As Hudd et al. (2011) note, once students are able to sift through larger texts to identify relevant information, then they can move into the next cognitive task of translating that information into their own words. This task is important in that it guides students toward thinking about the information differently from the ways in which it is explicitly presented initially. Students are using language that they are already familiar with in order to make sense of newer information they have had less exposure to. As the concentric model suggests, students can move into translation once they have mastered prioritization, and they can then begin moving into analogization once they have mastered both prioritization and translation.

The third cognitive task of the PTA model is analogization, in which students are instructed to map new information by drawing from information they already know well, resulting in the development of deeper levels of cognitive terrain. As Hudd et al. (2011) write, "this process of creating connections allows for the development of inferences, and learning occurs as new categories of knowledge are created" (p. 181). This series of cognitive tasks is beneficial for a number of reasons: 1) it specifically and purposefully guides students through more difficult levels of thinking; 2) instructors work alongside students to gauge their performance on these tasks; 3) writing is used as a tool to develop thinking, rather than as a tool used only for formal assessment; and 4) it is particularly well-suited to the structure of the flipped classroom due to its flexibility and its ability to grant students a greater sense of ownership over their learning and an awareness of the ways in which their learning has developed over time (Hudd et al., 2011). 


\section{The Flipped Classroom Approach}

Utilizing the PTA model in a flipped classroom has many benefits, but it is also important to understand how the flipped classroom fits within the disciplines of the social sciences, and sociology specifically. Berrett (2012) notes that while the flipped classroom has been common in the humanities for decades, this approach emerged in STEM disciplines by the emergence of technological innovation that allowed for students to access materials outside of the classroom setting in a convenient and cost-effective way, as well as with the demand for proof of "learning," also known as formal assessment. At the same time, professors have been faced with larger class sizes as a result of budget cuts, but are still looking to maximize student learning (Huggins \& Stamatel, 2015). Thus, many professors have turned to a flipped classroom approach in which the lecture material is presented outside of class, and then the more difficult "homework" is done during class, with the professor present to help guide and assist students with the material.

A common critique of the flipped classroom is that it seems difficult to assess whether or not students are actually completing the assignments outside of class. I often hear a variant of this question: "If you're not lecturing at them, then how do you know that they are 'getting' the material?" My response is generally in the form of a question: If you're lecturing at them, how do you know that they are "getting" the material? If students have access to a required textbook, then attending a lecture is often a repeat of that material that is already found in the textbook itself. If the material is repeated, then students would not be compelled to read the assigned readings in advance, since it will be a waste of their time. Many students informally report to me that they rarely use their textbooks for lecture-based courses, except perhaps to study right before an exam. They feel that the high price of textbooks is particularly unfair if they rarely use them. Implementing the flipped classroom is often an experience that both professors and students have reported finding more engaging and have been more fruitful in developing critical thinking skills (Rickles et al., 2013).

While there is no set formula for creating a flipped classroom, it generally involves the introduction of lower level cognitive work (e.g. reading an assigned chapter from a textbook) outside of class and then holding students accountable for that reading or other assignment by expanding upon that information through higher level cognitive work that occurs in the classroom itself. Below, I provide the rationale and example of such an activity that I often utilize in my introductory sociology courses, but I also use variations of it in other courses as well. ${ }^{1}$

\section{A WAC-based Writing-to-Learn Activity for the Flipped Classroom}

Writing Across the Curriculum (WAC)-based strategies for incorporating student writing in classrooms are particularly effective ways of encouraging student reflection and enhancing critical thinking skills. As Hudd and Bronson (2007) note, allowing students the opportunity to reflect on information through a recursive process allows them to develop 
metacognitive skills in order to build upon material learned and to be able to apply various forms of knowledge across different intellectual fields (see also Whitaker, 2017). This process is particularly helpful to students, as they "do not innately practice recursive learning processes in which they revisit ideas and adapt them in light of new information. Instead, they more commonly consider research and writing as a linear process: they compile and then present information" (Hudd \& Bronson, 2007, pp. 264-265). Writing also gives students a chance to practice "writing in the discipline" (WID) skills as well. ${ }^{2}$ Importantly, Grauerholz, Eisele, and Stark (2013) note a number of ways in which writing is linked to critical thinking and learning, in that writing serves as a tool. They state, "although writing is not the only pedagogical tool for facilitating and assessing learning, it is one of the most powerful" (Grauerholz et al., 2013, p. 47) in that it can facilitate higher-level thinking as well as having the unique capacity for revision and reflection. Not all writing assignments facilitate learning, such as writing for the sake of writing; Bean (2011) notes that writing should not be separated from the act of thinking and rather should be done with purpose.

While there is much research dedicated to the description of excellent reflexive writing assignments (both formal and informal, as I note below), this specific classroom activity is different for a number of reasons: 1) it can be explicitly situated within a flipped classroom because it involves introduction of course material outside of class with further exposure and reflection in the classroom; 2) it allows for multiple levels of engagement with specific course material as well as disciplinary-level ways of thinking; 3) it provides a specific example of what Hudd et al. (2011) refer to as the PTA model of concentric thinking that involves prioritization, translation, and analogization; and 4) it builds upon other literature (see, for example, Bean, 2011) by demonstrating a scaffolded development of a specific type of cognition practiced within the discipline of sociology: namely, "thinking sociologically" and what it means to actually do so. This assignment may help instructors in both facilitating sociological thinking as well as being able to note changes in such thinking over time as students are exposed to new material.

\section{Starting Outside of Class}

In this example activity, I am drawing from an exercise that I regularly use when students are first exposed to an introductory textbook chapter on race and ethnicity in the United States. This chapter in particular often tends to be anxiety-inducing amongst students for a number of reasons, but allowing for outside reflection to occur first is a preliminary way of assisting students in thinking about their own experiences, ideas, and assumptions around these concepts. For their homework that is due on the first day that we begin discussing this information, they are to read the textbook chapter on race and ethnicity and to watch a short news clip, produced by Buzzfeed, that is posted to their online Blackboard assignments. The news clip is entitled "José vs. Joe: Who Gets the Job?" and is only a few minutes long. In the clip, they watch an interview with a man named José who sent out his resume to over a hundred potential employers, only to receive 
zero callbacks. After becoming frustrated, José changed his name to Joe on his resume without altering any of the other information and immediately received dozens of callbacks asking him to come in for an interview. The news clip is an illustrative example of what sociologists call "institutional discrimination" and can serve as a "real-life" example of the ways in which institutionalized discrimination affects individuals on a daily basis. ${ }^{3}$

\section{Continuing Inside the Classroom}

The following day, during class, students are given the opportunity to reflect on the news clip they watched the night before. The day's activities will be guided by a series of three linked WTL informal assignments. Each section consists of the linked prompts that guide students through the PTA model. Therefore, the first prompt involves the prioritization of information, the second prompt asks students to translate information, and the third prompt guides students through the process of analogization.

\section{The First Prompt}

The first writing-to-learn (WTL) prompt is posted on the board at the beginning of class. This prompt asks students to reflect on the news clip that they watched last night. It gets them thinking about how they personally felt after watching it and what was the most important concept that they learned. Students are focusing on their individual feelings as well as prioritizing what information they believe to be the most salient to them.

Prioritization, as noted above, is the first and most basic task that a student must be able to complete, based on Hudd et al.'s (2011) model of PTA (prioritization, translation, and analogization). Again, this hierarchical model of thinking moves students through these three linked tasks so that they are ultimately able to make analogies amongst different texts, issues, ideas, or concepts.

As Bean (2011) notes, a WTL exercise is considered to be "low-stakes writing" in which the writing itself is graded rather informally, such as through a system of checks, check plusses, or check minuses, and that it is also "low-stakes graded" in that the assignment does not count for a substantial portion of a student's overall grade. Thus, students can feel empowered to explore difficult topics and reflect on the assignments without fear of getting it wrong or failing. It is an informal assessment that simultaneously fulfills a number of important requirements: that the student was in class on the day that the WTL was assigned (attendance); 2) whether or not the student completed the homework outside of class (low-stakes writing); and it serves as 3) fulfillment of a small part of the student's final grade (low-stakes grading).

In these types of series of prompts, I often combine WAC-based reflections with WIDbased reflections. In other words, my first prompt asks students to first engage with 
a WAC-based question, followed by a WID-based analysis in order to think about the content broadly in a way that might allow them to draw from their own background or previous course material. By allowing students to think about their own reaction and feelings regarding the clip, it can tap into lived experiences that allow them the ability to relate directly to the material; this is one way in particular that students engage in what sociologist C. Wright Mills calls the sociological imagination, or that perspective which "...enables us to grasp the connection between history and biography" (cited in Henslin, 2017, p. 3). In other words, when asking students to "think sociologically," instructors are teaching them to examine the ways in which one's social location, or the "corners in life that people occupy because of their place in society" (Henslin, 2017, p. 3) such as gender, race/ethnicity, and social class status. Using one's sociological imagination is precisely what sociologists refer to when one is "thinking sociologically." By engaging directly with course material, students develop WID-based skills by learning to think about course concepts and to write effectively using specific terminology in a disciplinarily appropriate way.

Based on my own experiences in developing and refining this activity over the past five years, I have found that by this point in the semester, students are very likely to be able to make connections to their own lived experiences. While some students are doing so at a somewhat superficial level, many others are able to link the ways in which their own biographies are shaped by privileges, geographic location, and socialization. By looking at the various layers and intersections of one's personal biography, students have often been able to engage in sociological thinking in order to make these connections explicit. Notably, this is not necessarily a skill that spontaneously emerges at this point in the semester unless a student has personally experienced some form of discrimination themselves; in other words, thinking about the ways in which a number of different social forces intersect in one's personal biography takes practice. I work regularly with students to discuss and write about what is meant by these particular terms and how to engage in sociological ways of thinking by incorporating similar writing activities throughout the semester.

\section{The Second Prompts}

In the second set of WID-based follow-up prompts, I then ask students to continue to think about the topic sociologically. That is, once students can personally reflect on the material, they then can demonstrate their knowledge of specific material from the appropriate chapter's reading while being able to make sense of a relevant social issue by thinking and writing "like a sociologist." Broadly, this way of thinking is central to the discipline of sociology itself; as the most recent American Sociological Association's Undergraduate Major Task Force Report notes, sociology contributes to a liberal education by "unfettering the mind," or, as Berger and Kellner (1981) note, sociology is a "... way of seeing, of seeing through things, and of going beyond the ordinary" (quoted in McKinney, Howery, Strand, Kain, \& Berheide, 2004, p. 1). 
Therefore, in the first part of this prompt, I ask students to think about some of the main concepts of our chapter on race and ethnicity that they have already read about, such as race, racism, prejudice, individual discrimination, and institutional discrimination. From there, they are expected to translate this information; in other words, they are asked to explain the relevant concept in their own words, which is the second of the three linked tasks of Hudd et al.'s PTA model. As a connected follow-up, students are asked to relate (or make analogies between) this concept in some way to the news clip, which serves as the third of the three WID-based linked tasks of the PTA model of concentric thinking. Thus, each scaffolded prompt is asking them to complete an increasingly difficult task of relating one piece of information to another.

In the second part of this prompt, students are then asked to think about the theoretical implications of the news clip. While this may sound like a daunting task, many introductory sociology textbooks not only introduce major theoretical frameworks at the beginning of the book, but they also repeatedly provide examples of major theoretical analyses across different chapters and concepts. Because the topical study of race/ethnicity is often not explicitly brought up until later on in the semester, students generally have greater exposure to not only the major theoretical perspectives themselves, but also to the varied ways in which such frameworks can be used to sociologically analyze particular topics as well. Therefore, it should not be unusual for a student to be prompted to think about one of the major theoretical frameworks they have already been discussing throughout the semester and to choose one that they believe helps best explain the issue(s) or concept(s) from the news clip. By asking the student to briefly explain the major theoretical framework they chose, I am again asking them to translate information, or to rephrase important information in their own words. From there, the follow-up prompt asks students to utilize that specific framework to analyze the news clip from a sociological perspective. ${ }^{4}$ Thus, the structure of the prompts also serves to scaffold students through the concentric thinking model of PTA.

Based on my own experience, students are equipped to begin working through translating important information in their own words if they have been able to prioritize information in an effective way during the first prompt. If a student is struggling with these specific prompts, one cause of this difficulty could be that they did not adequately understand the first prompt. In other words, students would have difficulty reframing information in their own words if they still do not understand what information "counts" as relevant or important to begin with. One challenge of "catching" struggling students, particularly at this point in the activity, is that unless there is some intervention or break in between prompts, it is unlikely that I would be able to know whether or not a student is falling behind. As a result, I have often asked students to pair up and discuss their writing and to report out their responses. If a student is having difficulty being able to prioritize and then translate information, I would then work closely with that student during the later prompts to assist them in ways of thinking about the material. While this is a particular challenge, I believe it to be very useful in ensuring that students are following through the steps of concentric thinking that will build them up to be able to analogize more 
difficult material.

\section{The Third Prompts}

The third set of prompts allows for the most synthesis amongst the previous activities, along with the most personal reflection. Because students are asked to read through their writing and think about their discussions with peers, they are then asked to revisit their older thoughts and follow through the recursive process of reflecting on the ways in which their feelings and thinking might have changed over the course of the day. This structure allows students to revisit the practice of making analogies, or the third task of Hudd et al.'s PTA model of concentric thinking. While the first prompt in this series asks students to reflect specifically on their own feelings, the second prompt is asking them to think about any new knowledge they might have gained from writing in class and from talking with their peers. These final prompts ask the student to think about what it means to engage in sociological thinking and how they might be personally affected by doing so. It is the process of using one's sociological imagination that may, in fact, create discomfort, and by addressing it head-on, these prompts may serve as a useful tool in allowing for knowledge growth in what could possibly be considered an otherwise uncomfortable topic.

Depending upon how quickly the class moves through completing the prompts, I often gauge whether or not I can introduce the third set of prompts on the board directly after we have covered the second set of prompts, or if I should either wait until the following class period or assign it as an out-of-class informal writing assignment. If the class meets for a longer period of time, then usually I would keep working through these tasks, but if I am teaching a particularly large class or if the class meets for a shorter period, I would most likely need to break the activity up. Based on my experience, students do just as well on the activity regardless of whether or not the prompts are broken up. There is much flexibility in the timing and discussion of these prompts; they should be given in this order, however, to provide adequate scaffolding and to allow students to move from prioritization, through translation, and into analogization.

Because of the scaffolded nature of this activity, I have often used variations of it toward the development of a larger, perhaps more formal end assessment such as a paper or project. For example, students in my introductory courses are instructed to complete a final project that demonstrates the development of their sociological thinking across the semester. Their previous responses to various course material are an invaluable resource to them for this project because it reflects their sociological thinking and its refinement over time. I have also utilized student responses to either facilitate additional in-class discussion or lead into other activities or formal assignments. ${ }^{5}$ In my experience, students often report that they might not otherwise participate in class discussions because they either have not thought much about a topic or because the topic itself may be considered controversial or emotionally-laden. However, because they already have written down a response to the prompt, they may be more willing to positively contribute 
to such discussions and to participate in group work as well. Active class participation in sociology courses may be more difficult to achieve given the potentially controversial nature of many of the topics that are routinely discussed. Because some students may not have had to consider their social location and how they may institutionally benefit from their group statuses, the very nature of discussing inequality and unequal access to societal resources can become emotionally-laden and potentially prone to conflict. However, given that the discipline itself might be considered by some to be controversial, it seems important to recognize this discomfort and be supportive of students while also being able to teach the course material in a sensitive and informative way. In fact, it is this discomfort that can be analyzed sociologically; that is, such feelings of discomfort are actually the result of one's connections between the personal and social, or one's social location, and these issues can be theoretically described and systematically studied. Therefore, one way of achieving this balance is specifically through the use of in-class informal writing that allows students to get their thoughts on paper before any open discussion occurs.

\section{Benefits and Weaknesses of This Activity}

While it has been an on-going process of refining the material and the prompts over a number of semesters, I have found that the general structure of the assignment itself consistently allows for greater understanding of course material by bringing in timely and relevant information. Because the structure of the assignment is recursive and scaffolded, other instructors can implement variations of it in which they may incorporate material that is directly relevant to their specific course material. The scaffolded nature of the assignment means that students start from a place where they can begin making surface-level connections, and through completion of the prompts, it allows them the opportunity to work on increasingly more difficult cognitive tasks as the PTA model describes (see Hudd et al., 2011). It is a versatile, flexible assignment that, with some preparation, can be quickly incorporated into virtually any classroom, and it can also be informally graded in a timely manner (if the instructor so decides). I often also use variations of this activity as a tool to informally gauge where students "are at" with the material as whole. For example, if students are responding to the prompts only superficially and are not able to prioritize information or to make connections between the outside material and the course material, then it may signal to me that I may need to incorporate more basic prompts in order to "build students up" to be able to answer these prompts appropriately and proficiently.

As Horn (2013) recently suggests, however, there are potential weaknesses of the flipped classroom approach. For example, although students should ideally be moving through the course material at a self-directed pace, most flipped classrooms cannot accomplish this flexibility in reality. Furthermore, as Horn notes, flipped classrooms that require Internet access and technology outside of school may further exacerbate inequalities among students who do not have such access to begin with. 
Since flipping my own classroom, I have observed that overall, student performance on most assessments improved across semesters. In other words, average exam grades were higher in courses in which students were exposed to the flipped classroom versus the traditional lecture - and those assessments were not modified in any way between the two classroom conditions.

It was clear that students took ownership of their learning and also reported that they did so as well. Students were more likely to bring their textbook to class and to complete the assigned readings than if they were going to be lectured on that same information in class. Not only were students more likely to report that they did complete the readings, but they also seemed more likely to be able to demonstrate to me as well as to other students that they did so by drawing explicitly from the readings to support in-class activities.

As a result, class participation and active engagement with the material also increased. Students asked more questions about the nuances of particular issues in class and were more likely to respond to questions that I and other students raised as well. Importantly, students took less time taking notes, and they were less likely to ask what was going to be on the exam. Finally, I also noticed that my teaching evaluations improved across semesters.

Why might these positive changes have occurred? Students reported that they were able to connect course material to lived experiences and socially relevant examples in order to increase meaning-making. While there is an increase in the amount of time I spent planning ahead for each specific class, I spent less time having to reteach specific material to individual students who were not paying attention in class, and I also spent less time dealing with students who were not happy with their grades on various assessments. While it might seem daunting to drastically restructure and modify one's pedagogical technique, especially when it involves something so deeply entrenched within our own life experiences and the expectations of our students, I have found that utilizing the flipped classroom and implementing examples of reflective writing in class has been a positive experience for both professors and students alike.

\section{The assignment: Writing-to-Learn Activity for a Flipped Classroom}

See the Supplementary Files for this article at thepromptjournal.com for a PDF facsimile of the original formatting of this assignment.

\section{Outside of Class:}

1) For class tomorrow, please read the textbook chapter titled "Race and Ethnicity in the United States." 
2) Please watch the following link: https://www.youtube.com/watch?v=PR7SG2C7IVU

3) Prepare to come to class being able to write about and discuss the information that you have learned about!

\section{In Class:}

1) First student Writing-to-Learn (WTL) prompt:

- Spend a few minutes thinking about the news clip you watched last night. How do you feel after watching this clip? What was the most important issue or concept that you learned from watching it?

2) Second set of student WTL prompts:

A) Now, think about one of the main concepts of our chapter on Race and Ethnicity that you've already annotated on your own.

1) How would you explain this concept?

2) How does this specific concept relate to or help explain the issue(s) you learned from watching the news clip?

B) Think about one of the three major theoretical frameworks we have been discussing this semester that you think helps best explain the issue(s) or concept(s) from the news clip.

1) Briefly explain the major theoretical framework you chose.

2) How can you use that framework to analyze the news clip from a sociological perspective?

- [If you have been instructing students on what it means to "think sociologically" throughout the semester, you might want to end the second part of the prompt with: "In other words, think like a sociologist!" for additional guidance.]

3) Third set of student WTL prompts:

A) Read through all of your writing today and think about the discussions you've had with your peers. Have your feelings regarding the news clip changed in any way? If so, how? If not, why do you think this is the case?

B) What new information did you learn today from writing out your responses and sharing them with others?

Acknowledgments: The author would like to thank Suzanne S. Hudd for her invaluable assistance and guidance through earlier iterations of this work, as well as the reviewers for their helpful and insightful feedback. 


\section{Notes}

\footnotetext{
${ }^{1}$ This type of activity can also be used in a number of other disciplines such as history, anthropology, psychology, political science, and women's studies, to name a few. The structure of the activity itself, however, is potentially applicable to virtually any course.

${ }^{2}$ For a brief history and overview of the WAC and WID-based literature, see Thaiss and Porter (2010).

${ }^{3}$ For a more in-depth discussion of this particular individual's situation, please visit http://www.huffingtonpost.com/2014/09/02/jose-joe-job-discrimination_n_5753880.html_or http://www.businessinsider.com/job-seeker-changed-his-name-2014-9.

${ }^{4}$ The previous paragraph includes a number of basic assumptions that I have made regarding the structure of an introductory sociology course. While I believe that I am describing a common theme of introductory courses in that students are first introduced to basic theoretical frameworks and then use those frameworks throughout the semester to analyze social concepts, I recognize that instructors may structure their courses differently. If this is the case, then in order to effectively utilize these prompts, it would be essential for the instructor to provide materials that allow students the ability to familiarize themselves with basic sociological theory and practice.

${ }^{5}$ For example, see Kaufman (2013) for an excellent description of reflective in-class writing used in conjunction with an in-class activity; Picca, Starks, and Gunderson (2013) for an example of student journaling that may also enhance in-class discussion; and Parrott and Cherry (2014) for a discussion of process memos that improved feedback and dialogue between students and instructors regarding major writing assignments.
}

\section{References}

Bean, J. C. (2011). Engaging ideas: The professor's guide to integrating writing, critical thinking, and active learning in the classroom (2nd ed.). San Francisco: Jossey-Bass.

Berger, P., \& Kellner, H. (1981). Sociology reinterpreted. New York: Doubleday.

Berrett, D. (2012, February 19). How "flipping" the classroom can improve the traditional lecture. The Chronicle of Higher Education. Retrieved from https://www.chronicle.com/ article/How-Flipping-the-Classroom/130857

Brame, C. J. (2013). Flipping the classroom. Retrieved January 2, 2013, from http: //cft.vanderbilt.edu/guides-sub-pages/flipping-the-classroom/

Fulton, K. P. (2012). 10 reasons to flip. Phi Delta Kappan, 94(2), 20-24. http: //doi.org/10.1177/003172171209400205

Grauerholz, L., Eisele, J., \& Stark, N. (2013). Writing in the sociology curriculum: What types and how much writing do we assign? Teaching Sociology, 41(1), 46-59. http://doi.org/10.1177/0092055x12461453

Henslin, J. M. (2017). Essentials of sociology: A down-to-earth approach (12th ed.). Boston, MA: Pearson.

Horn, M. B. (2013). The transformational potential of flipped classrooms. Education 
Next, 13(3), 78-79.

Hudd, S. S., \& Bronson, E. F. (2007). Moving forward looking backward: An exercise in recursive thinking and writing. Teaching Sociology, 35(3), 264-273. http://doi.org/ $10.1177 / 0092055 \times 0703500305$

Hudd, S. S., Smart, R. A., \& Delohery, A. W. (2011). "My understanding has grown, my perspective has switched" Linking informal writing to learning goals. Teaching Sociology, 39(2), 179-189. http://doi.org/10.1177/0092055x11401563

Huggins, C. M., \& Stamatel, J. P. (2015). An exploratory study comparing the effectiveness of lecturing versus team-based learning. Teaching Sociology, 43(3), 227-235. http://doi.org/10.1177/0092055x15581929

Kaufman, P. (2013). Scribo ergo cogito: Reflexivity through writing. Teaching Sociology, 41(1), 70-81. http://doi.org/10.1177/0092055x12458679

McKinney, K., Howery, C. B., Strand, K. J., Kain, E. L., \& Berheide, C. W. (2004). Liberal learning and the sociology major updated: Meeting the challenge of teaching sociology in the 21st century. Washington, DC: American Sociological Association.

Mills, C. W. (2000). The sociological imagination. London: Oxford University Press.

Moore, A. J., Gillett, M. R., \& Steele, M. D. (2014). Fostering student engagement with the flip. Mathematics Teacher, 107(6), 420-425.

Parrott, H. M., \& Cherry, E. (2014). Process memos: Facilitating dialogues about writing between students and instructors. Teaching Sociology, 43(2), 146-153. http: //doi.org/10.1177/0092055x14557440

Picca, L. H., Starks, B., \& Gunderson, J. (2013). "It opened my eyes" Using student journal writing to make visible race, class, and gender in everyday life. Teaching Sociology, 41(1), 82-93. http://doi.org/10.1177/0092055x12460029

Rickles, M. L., Schneider, R. Z., Slusser, S. R., Williams, D. M., \& Zipp, J. F. (2013). Assessing change in student critical thinking for introduction to sociology classes. Teaching Sociology, 41(3), 271-281. http://doi.org/10.1177/0092055x13479128

Sams, A., \& Bergmann, J. (2011). Flipping the classroom. Educational Horizons, 90(1), $5-7$.

Thaiss, C., \& Porter, T. (2010). The state of WAC/WID in 2010: Methods and results of the US survey of the international WAC/WID mapping project. College Composition and Communication, 61(3), 534-570.

Whitaker, J. (2017). Recursive exercises to help students engage and recognize sociological shifts. Teaching Sociology, 45(1), 14-27. http://doi.org/10.1177/0092055x16664958 